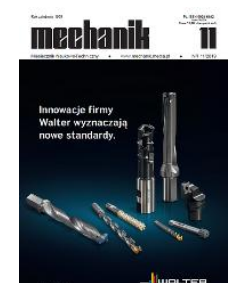

How to cite this article:

Authors: Piotr Szulewski, Dominika Śniegulska-Grądzka, Mirosław Nejman

Title of article: „Intelligent sensors in modern machine tools”

Mechanik, No. 11 (2019)

DOI: https://doi.org/10.17814/mechanik.2019.11.91

\title{
Intelligent sensors in modern machine tools
}

\author{
PIOTR SZULEWSKI \\ DOMINIKA ŚNIEGULSKA-GRĄDZKA \\ MIROSŁAW NEJMAN *
}

\begin{abstract}
Dr inż. Piotr Szulewski, maxer@cim.pw.edu.pl, piotr.szulewski@pw.edu.pl, https://orcid.org/0000-0002-0821-3946 - Instytut Technik Wytwarzania, Politechnika Warszawska, Warszawa, Polska

Dr inż. Dominika Śniegulska-Grądzka, dominika.gradzka@pw.edu.pl, https://orcid.org/0000-0001-6418-5938 - Instytut Technik Wytwarzania, Politechnika Warszawska, Warszawa, Polska

Dr inż. Mirosław Nejman, m.nejman@zaoios.pw.edu.pl, https://orcid.org/0000-0003-4418-019X - Instytut Technik Wytwarzania, Politechnika Warszawska, Warszawa, Polska
\end{abstract}

The paper illuminates the basic information on the use of sensors in industrial measurement systems with particular reference to machine tools. The most important technical-utility parameters were presented and criteria helpful in the selection of sensors for practical applications were indicated. The latest generation of intelligent sensors was also presented, focusing on their possibilities of cooperation with information systems (Internet of Things) and the idea of Industry 4.0.

KEYWORDS: Industry 4.0, intelligent sensors, monitoring and supervision, IoT

\section{Introduction}

The modern machine tools are sophisticated devices, are built form numerous elements, assemblies and subsystems (body, drivers, controllers, etc.) and together they ensure the machining process, which often consists of many advanced procedures and operations [1]. The process need to be continuous monitored in order to ensure required machining accuracy, high quality and acceptable cost of manufacturing [2]. An additional problem is availability and use of machine tools that will allow continuous production maintenance and execution of planned schedule. In the current market conditions, avoiding equipment and tools failures, advance planning of maintenance and repair activities have become a necessity and a real challenge for CNC machine tools designers [3].

Application of appropriate sensors would seem to be the only effective method of obtaining as complete as possible information about current process and machine state. They allow for collection of data in significant parameters and physical properties and also analysing selected signals measures [4]. It is the necessary condition of effective introduction Industry 4.0 concept in workshop conditions [5, 6].

Detector/sensor (Latin. sentire/sensum - this, who feels) is a element of automatic system responsible for creation of signal providing information on the state of the monitored process or device [7]. The working principle of the sensors is active processing of selected physical quantity (its changes), usually on the volume of electricity, easy to measure and for further processing. This kind of electric value is e.g. voltage, current or frequency. Sensors are counted as a first element of measurement path. The measurement is understood as representation of the real image (process) in the image of abstraction (information) resulting from comparation of measured quantity with approved pattern [8].

Sensors which can be found in measuring technology are divided into:

- analog - signal processing does not change its continuous nature, and measurement result is presented as analogue signal within the time function,

- digital - occurs the process of digitalisation of continuous measuring signal (analog-digital processing), and measurement result is presented in digital form (discrete).

Also popular is sensors division into active (require delivery of energy to generate a measuring signal, e.g. thermistor) and passive (signal energy is taken from observed phenomenon, e.g. thermocouple). 
In industrial automation are usually used voltage signal in ranges: $0 \div 10 \mathrm{~V}, \pm 10 \mathrm{~V}, \pm 5 \mathrm{~V}$, digital: TTL and CMOS and current: $0 \div 20 \mathrm{~mA}$ and $4 \div 20 \mathrm{~mA}$. While selecting the sensors can be concluded many helpful criteria. As a primary shall be listed: owned by sensor the expected range of changes in the measured value, required/preferred way for further measuring signal use, adjust to static characteristics (accuracy) and dynamic measuring systems (transmittance), fulfillment of environmental requirements, minimising sensor impact on machine tool process and status, sensitivity, insensitive to interference and reliability [9].

In industrial automation sensors are normally use to measure: position, linear and angle (rotational) speed, linear acceleration or object angle speed and acceleration in its own reference system (accelerometers and gyroscopes), forces, torques, stresses, pressures, deformations, rigidity, weights, density, viscosity, stream, environment (temperature, humidity, pressure, noise level), electrical properties (e.g. voltage, frequency, current, active and reactive power) etc. Due to the principle of operation, the sensors can be classified as: potentiometric, capacitive, inductive, ultrasonic, tensometric, piezoelectric, piezoresistive, photoelectric, electromagnetic etc. $[10,11]$. There is a frequently existing need for processing the form of measuring signal (shape or progress), to obtain signal, that has more favourable properties than original progress from detector/sensor. The most common activities are: reinforcement, filtration, straightening, modulation, discretization or encoding [12].

When developing a measuring system to obtain valuable information (monitoring) about machining center or machining process state, it becomes necessary to compliance with general principles related to the construction of the measuring track. It is important to ensure that:

- matching the measuring characteristics (static and dynamic) of the used components (e.g. compatible and sufficient measuring ranges - variation ranges of output and input values cooperating elements must be the same),

- the highest resistance of the measuring circuits, which will minimize the power load of the observed objects/systems,

- avoiding harmful inductive and capacitive couplings between sensors and devices that may be a source of adverse parasitic phenomena's (noise and harmonics),

- limitation the appearance and spread of an undesirable constant component of variable signals,

- measuring system simplification (minimizing number of components or circuits in the system) [13].

Basic technical parameters, which determine sensor are:

- Measurement dynamic range is indicated by ratio of sensor maximum input value to minimum, but still measurable input signal value. Dynamic range value is often expressed in decibels. For quantities like voltage and current, this is the formula:

$$
K_{\mathrm{u}}[\mathrm{dB}]=20 \log _{10}\left[\frac{U_{2}}{U_{1}}\right]
$$

where: $K_{\mathrm{u}}$ - voltage/amplitude ratio; $U_{1}$ - voltage/reference amplitude; $U_{2}$ - voltage/measured amplitude.

For example, voltage ratio $1 \mu \mathrm{V} / 1 \mathrm{~V}$ value $K_{\mathrm{u}}$ will be $120 \mathrm{~dB}$. For power ratio formula can be shown as:

$$
P[\mathrm{~dB}]=10 \log _{10}\left[\frac{P_{1}}{P_{0}}\right]
$$

where: $P_{1}$ - measured power; $P_{0}$ - reference power; $P$ - power ratio.

- By measuring resolution concept means a minimum difference between the two values, which is detected by sensor (obviously above own noise value). In the case of analog sensors, the resolution usually corresponds to lower limit dynamic range. Digital sensors resolution depends on measuring range of converter $\mathrm{A} / \mathrm{C}$ and number of signal levels, which it can measure in this range (data word width number of bits). For instance: for digital sensor measuring the voltage in range $0 \div 10 \mathrm{~V}$ with 12 -bit converter $\mathrm{A} / \mathrm{C}$ resolution is $10 \mathrm{~V} / 4095 \approx 2.4 \mathrm{mV}$.

- Frequency band - is limited by the speed of the sensor response to changes in the measured value and defines the maximum and minimum signal frequency value that can be measured by the sensor.

- Linearity determines the ratio between sensor input and output. For two inputs $x$ and $y$ (at the corresponding outputs identified $f(x)$ and $f(y)$ ), for any numbers $A$ and $B$ is fulfilled equation:

$$
f(A x+B y)=A f(x)+B f(y)
$$

- The ratio of the output signal change to measured value change is assumed as sensor sensitivity. Sometimes sensitivity is also defined as the slope-dependent of the output signal from the input.

\section{Intelligent sensors}

Various sensors and converters are mounted in machine tools for more than two decades. One of their most important (actually the first) applications was to increase the protection of both the machine and the process 
against the effects of failures, malfunctions of components or collisions. The control system equipped with the appropriate sensors (e.g. position measurement, force) can, if necessary, react within milliseconds, which is one thousand times faster than trained operator. However, at present to gain advantage in the competitive and global market the company must offer manufacturing of a large range of products the full potential of personalization, flexibility and the lowest possible production costs. The condition for achieving such state is undertaken non-standard actions directed towards the maximum use of the existing machine park. This is inextricably linked to the need for introducing complete monitoring of all machine tools and for performed process. It enables immediate problems identification and taking fast and efficient actions minimizing their negative effects [15].

Continuous and effective informatics and microelectronic development allowed creating completely new class of devices fitted with advanced functions and carrying out complicated measurement algorithms. Intelligent sensors (smart sensors), that contain measuring element (typically solid state) with special electronic circuits are increasingly popular. The first examples of this type of device at the end of the 80s. and since then they are in constant state of change. Presently they become very complicated components with wide measurement and functional opportunities [16]. On the basis of the possibility of taking advanced actions by sensors, the devices are divided into:

- regular sensors - which process measured physical quantity into an electrical quantity (e.g. electromotive force SEM, charge, resistance change),

- integrated sensors - with integrated processing elements (e.g. amplifiers. filters, conditioner, converters $\mathrm{A} / \mathrm{C}$,

- intelligent sensors - in their structure there are programmable systems and micro-controllers allowing advanced signal processing and ensuring communication with upper-level systems.

Schematic diagram of modern, intelligent sensor structure is shown in fig. 1.

These sensors - thanks to additional systems and software (intelligence) - permit the efficient supersaturation relevant information obtained during the measurement. These data are processing quickly, accurately, locally and safely sent to recipients.

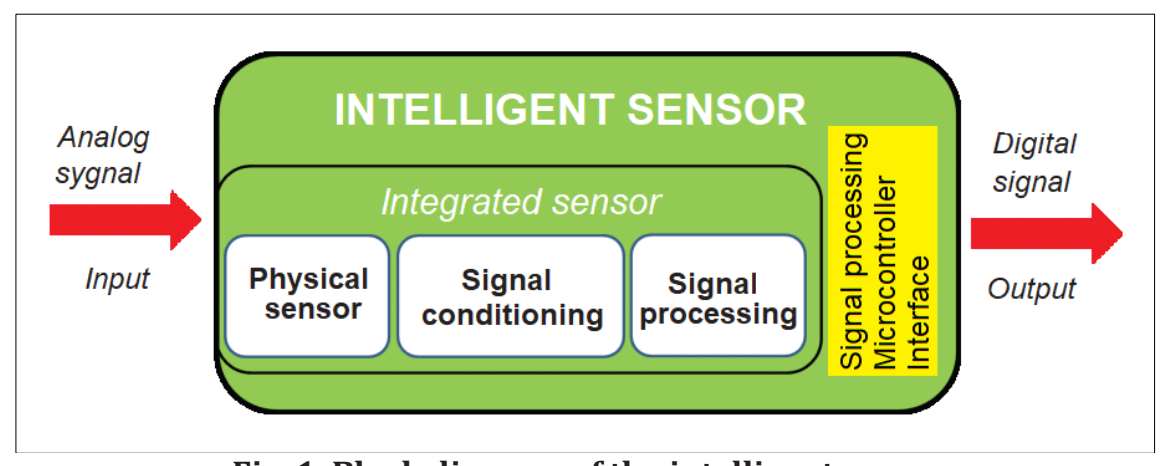

Fig. 1. Block diagram of the intelligent sensor

The extensive communication functionality enables considerable simplification of measurement system structure $[17,18]$. The most important functions provided by intelligent sensors:

- effective, programme linearization (compensation) measuring characteristic used converter, increasing measuring accuracy and remove impact of outside factors (temperature, pressure),

- autocalibration, "all by themselves" zeroing, adjustment, comparation with adopted pattern,

- automatic measurement system adjustment for measurement conditions and measured quantities,

- registration and data storage in the case of communication loss with upper-level systems,

- data compression and initial statistics of obtained results,

- full self-diagnosis (autotest) sensor status (e.g. temperature drift), errors detection,

- striving for self-reparability,

- data exchange using defined protocol,

- system operation (parameters, modes, etc.) of individual components (e.g. converters, amplifiers),

- ability to self-learning and autonomous inference,

- interaction with other sensors in groups and in swarms.

Intelligent sensors are the basis of popular system Internet of Things and its industrial version - IIoT

(Industrial Internet of Things). It must be remembered that the key feature that distinguish industrial devices form consumer devices is trouble-free operation and relatively long time of use. It is assumed that the average time of industrial device proper functioning oscillate between $7 \div 10$ years [19]. Projected success of IoT/IIoT, 
as it seems, will only be possible for the creation of areas that solve actual problems. The key tasks of these systems can be divided into three main categories:

- technical: miniaturisation, more computing power, reduced energy consumption, open communication,

- algorithmic: more advanced data processing algorithms focused on specific, particular task/application,

- completeness: willingness to carry out practical work right after the power is supplied [20].

Internet of Things information structure consists of several hierarchical arranged levels, which (in typical application) can be defined as operation stages of artificial intelligence. And so, respectively: unprocessed measurement data, analysed and processed, allow the detection of changes in the measured quantity, give the possibility of complete monitoring of the current device state and allow the introduction of context awareness (knowledge) about the way the device operation (behaviour patterns as a function of time) by detecting the causes of state changes and, as a result, predicatively deduce the machine's future state and behaviour. This type of actions seem very attractive, because in case of their success they will allow the emergency situations elimination and ensure entire production continuity, maintaining the highest achievable quality and acceptable manufacturing cost. Currently, research on the introduction of work method of these systems consistent with the functions of the human brain - as the most sophisticated association, mechanisms of associating, reasoning and planning was carried out [21]. The exemplification of this concept is shown in fig. 2.

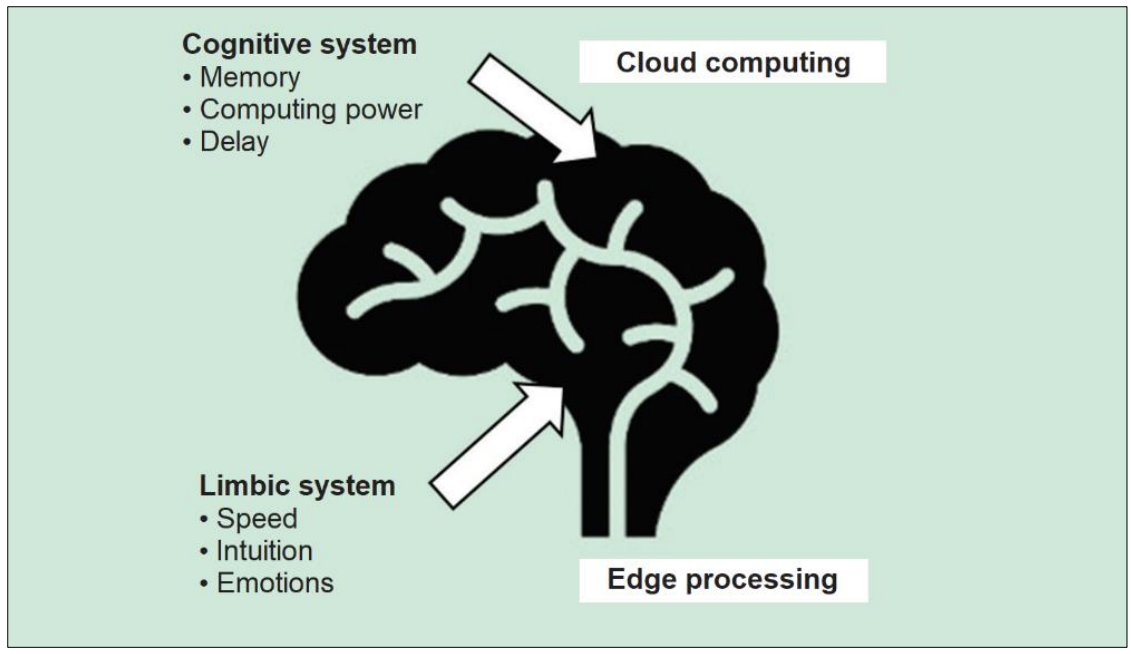

Fig. 2. Two basic ways of data processing

In accordance with established views rational being brain has two data processing systems (fig. 2): cognitive and limbic.

In the cognitive mode, very large volume of data are processed in relatively significant time periods - there is a variable delay, but the results are based on in-depth analysis and can give a stable basis for further action. Comparing this model to technical representation, it can be associated with modern cloud computing (memory, computing power, latency). Its opposite is the limbic system (marginal system), treated as primary, reactive and reflective, responsible for emotional behaviour regulation. In technology, its equivalent is local edge processing, carried out directly in the area of sensors [22].

This results in a very important function, in which intelligent sensors must be equipped. It is associated with the need to make autonomous decisions - e.g.: which of the obtained data are important enough to transfer them to the cloud (where they will be analysed), and which information should be processed locally in the sensor [23]. Such action allows very efficient use of available network capacity and computing power, at the same time not reduce the quality of acquired knowledge and precision of machine or process monitoring. Effective and effective decision algorithms, similar to the intuitive determination of data verification criteria are a good basis for this process.

\section{Sample solutions}

As already indicated, all activities of components, subassemblies and industrial automation systems producers are intended to ensure the highest possible process efficiency of machinery. They are looking for system solutions characterized by transparency, efficiency and continuous communication, from the single sensors to entire devices groups operating in production lines and halls. It aims to optimize, reduce costs and continuous production monitoring. 


\section{Control the machining process}

To measure physical phenomena from the cutting process, sensors should be placed as close as possible to the cutting area. In production conditions, the limitations for the sensor installation are the complexity degree of machine tool mechanisms (supplying power to the sensors and output of measuring signals, hermeticality of sensor-wire connectors, wires and sensorresistnce to chemically aggressive coolant and sharp chips, which can quickly cut even metal, reinforced cable covers). For these reasons, every innovation in the field of sensors adaptation for measurements close to the cutting zone is extremely valuable.

An example can be the active vibration damper for Sandvik Silent Tools ${ }^{\mathrm{TM}}$ turning tools (fig. 3), in which a sensor is incorporated, that allows to control the inclination angle of the tool cutting edge and set the blade at the level of the rotation axis. The tool holder is equipped with measuring systems communicating with the control and tool operation software via Bluetooth and enabling measured data visualization in real time:

- tool contact with machining material and temperature of vibration reduction module,

- surface roughness level and vibrations,

- load and deflection.
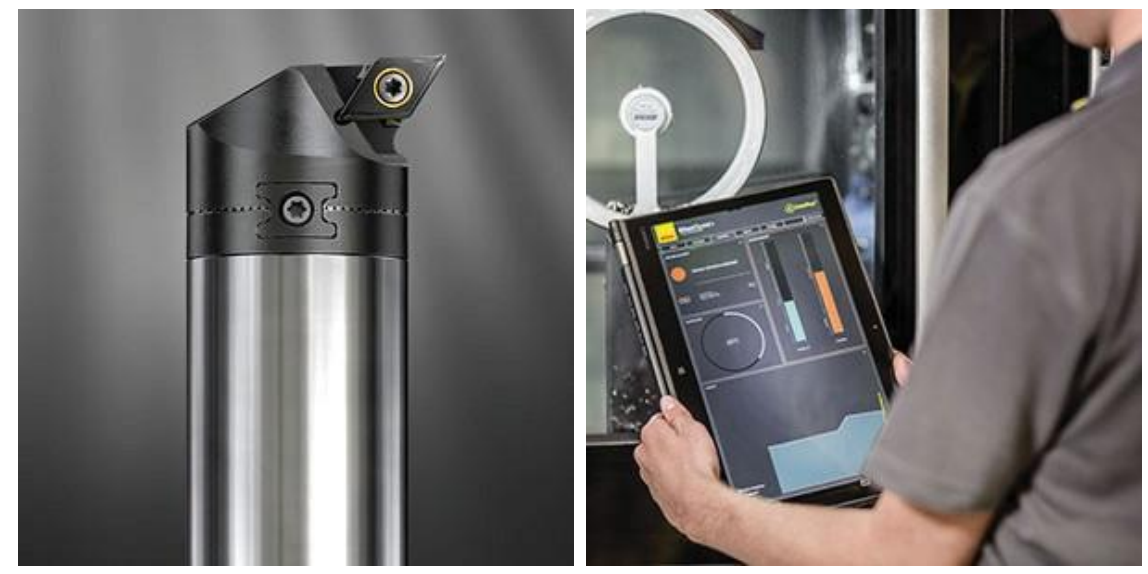

Fig. 3. Active vibration damper for turning tools [25]

Another example is the drive head of rotary tools for turning Coromant Capto ${ }^{\circledR}$ DTH Plus applications (fig. 4). Built-in sensors allow the self diagnosis in view of planned head maintenance and detection of excessive tool wear. There is real-time access to information such as: remaining estimated operation time, battery charge level, machining vibration level, rotational speed and direction of rotation and head working temperature.

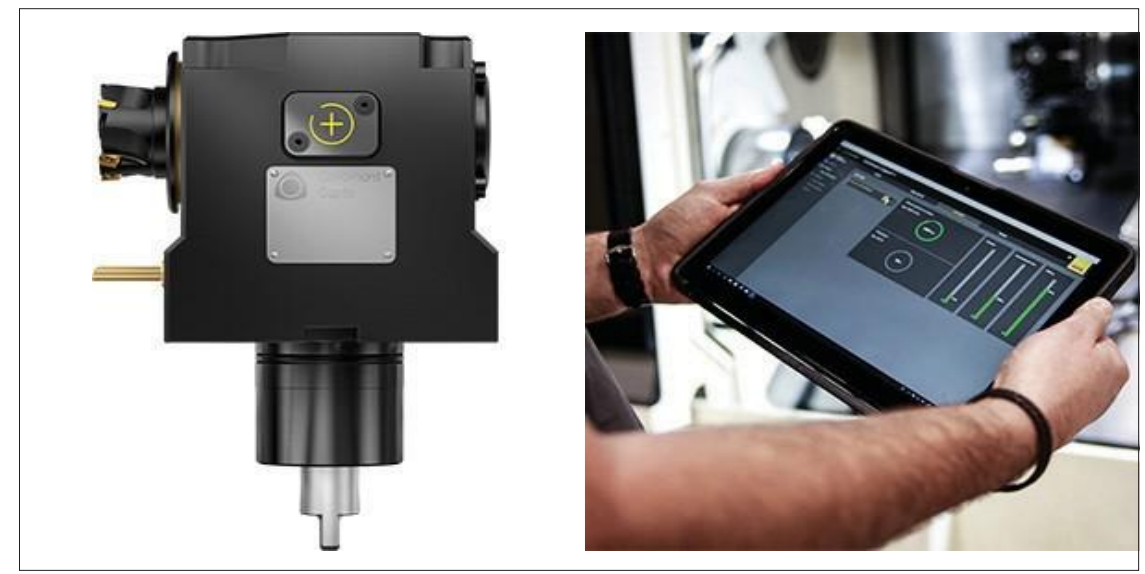

Fig. 4. Driven tool holder [26]

\section{Wireless data transmission from movable and rotary parts of working machines}

A frequent problem of moving and rotating machine parts monitoring is lack of recourse to wire voltage supply to the sensor and transmission via a measuring signal cable to and from the sensor. The company PCB 
Electronics offer universal telemetric systems, which can be battery-operated or using transmission RF (radio frequency). This solution is actually maintenance-free compared to systems required cable routing (which move or bend) or using brushes (contacts) in signal transmission. System PCB series 8179 and 8180 (fig. 5) has a compact size, mass from $4 \mathrm{~g}$, it is resistant to shocks, dirt, water resistance and enables wireless calibration. Supports extensometers, thermocouples, thermoresistors or provides voltage measurement.

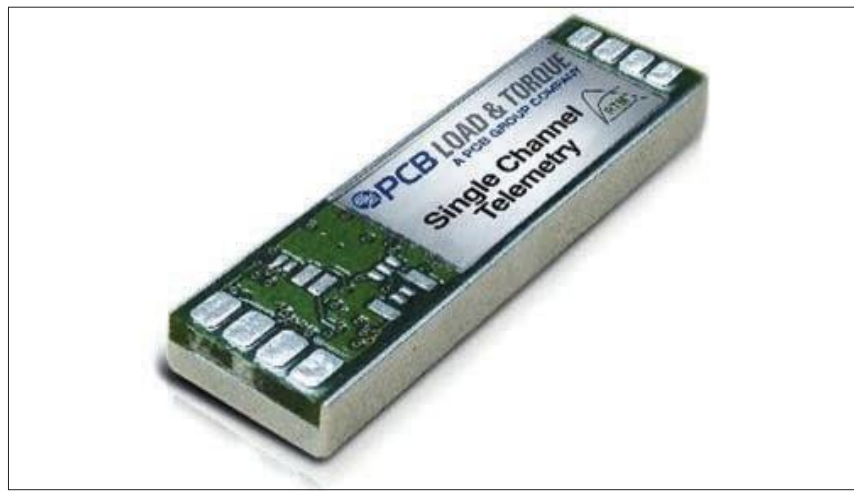

Fig. 5. Single channel telemetry system PCB Electronics 8180-RE110A [27]

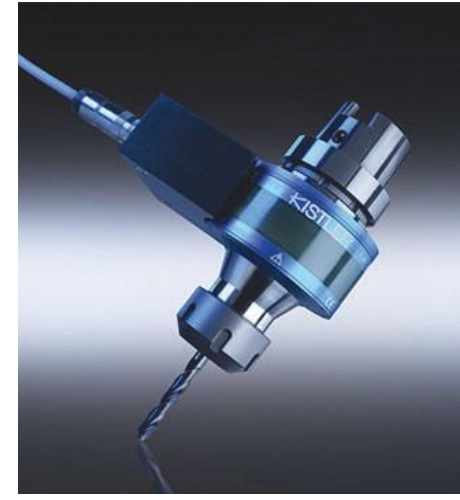

Fig. 6. Rotating dynamometer Kistler 9170A [28]

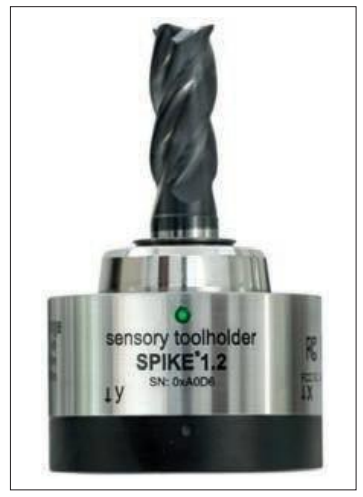

Fig. 7. Spike dynamometer from promicron [29]

Measuring systems for measuring cutting forces and moments are also available. An example is the dynamometer spike from company pro-micron (fig. 7) or rotatory dynamometer from company $9170 \mathrm{~A}$ (fig. 6). In both solutions, the signal from the sensor is transmitted by radio, which allows forces measurements very close to the cutting zone. The sensor retooling into further cutters or drills is problematic. If the production process provides for use of many tools, then having many such dynamometers (a separate dynamometer for each tool) is very expensive. It is also inviable (due to downtime at work) to attach subsequent tools in the same dynamometer during a single operation.

\section{Contact-less test of machine tools movement accuracy}

EASY-LASER E940 Machine Tool (fig. 8) is measuring system to accuracy testing of machine tools measurements. System is universal and could be used to testing: turning, milling, drilling machines, press, water jet cutting machines, etc. Its use includes, among other: straightness testing of the machine axis, soindel actual position, spindle axis inclination, perpendicularity between machine tool axles, table flatness or machine tool bed or wheel hub bearing control. It completely replaces traditional methods with touch probes or dial indicators. Digital data archiving allows to rapid data generation for machine movements compensation, if it does not provide straight movements.

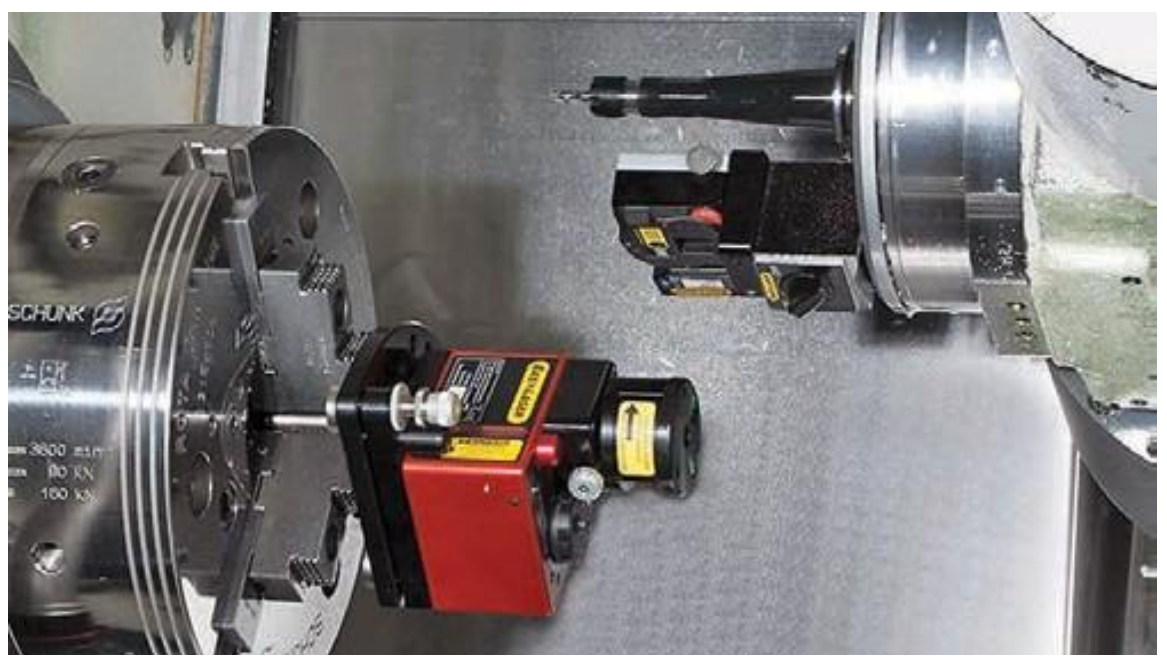

Fig. 8. EASY-LASER E940 Machine Tool measuring system [30] 


\section{Bearing condition monitoring}

An innovative solution for bearing monitoring is a sensor built into a FAG bearing with a VarioSense module, which can monitor: rotational speed, temperature, displacement, rotation angle, direction of rotation, load and vibration/acceleration (fig. 9). It may replace existing bearing, if in axial direction there is a place for additional $7 \mathrm{~mm}$. Bearing wear can also be monitored with adequate module of company Schaeffler (bearing producer).

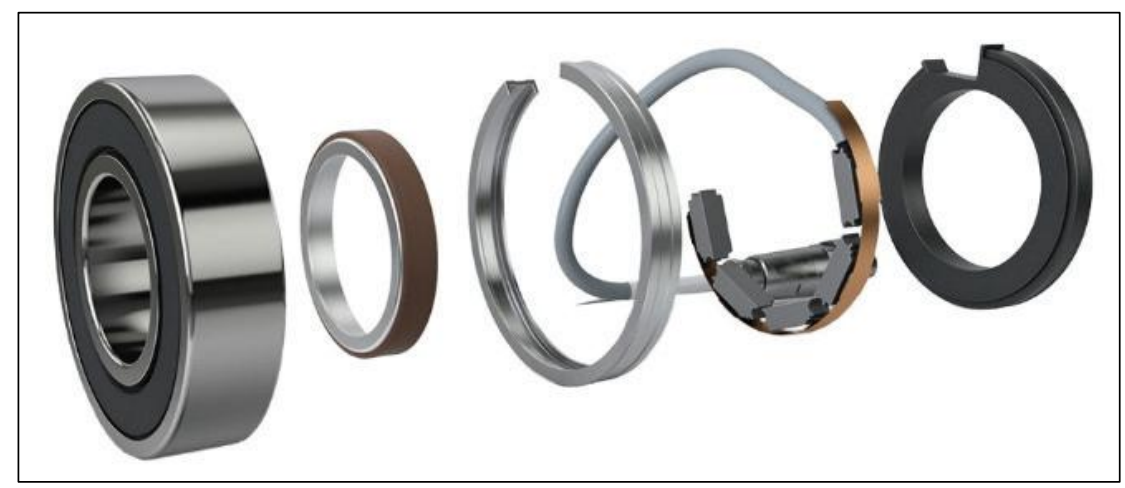

Fig. 9. FAG VarioSense bearing [31]

\section{Distributed network of sensors with IO-Link interface}

IO-Link system - independent of producer's communication system type point-point (IEC 61131-9) provides connections of various types of sensors and execution units (actuators) to the automation system. This consists of device Master IO-Link, which is the interface to the control system or field bus level. It communicates with one or more devices IO-Link that can use network standards Profinet, Profibus, EtherCAT, CC-Link, EtherNet/IP or DeviceNet. IO-Link is an international standard working with all commonly used field buses and control systems. Employed by manufacturers such as ifm, Balluff, Turck or Sick. It enables reliable signals transmission from binary sensors, process values of analog sensors and their parameters in a digital form and based on a $24 \mathrm{~V}$ signal. Today, sensors IO-Link offer completely new opportunities in accordance with Industry 4.0 development. For example: additional sensor data is generated, which can be used to ensure maximum efficiency and savings of processes, and there is process transparency from machine to system ERP, which allows maximum optimization of the existing industrial automation system. Sensors with IO-Link are characterised also by:

- interference resistance - due to direct digital signal transmission, the measured values do not lose accuracy and they are not susceptible to interference during transmission to the control system, as in the case of analogue signals (fig. 10a); digital data transmission cable (fig. 10b) do not require grounding and the signal is not susceptible to interference, as in the case of measuring cables with analogue signals, which must be shielded, grounded; in sensors with digital outputs as a rule, analogue signal is optional and then there is a multiple conversion of digital to analog form, which together with analogue transmission loss may cause measurement errors up to $1 \%$ or more; in fig. 11 is shown example of a pressure sensor with an interface IO-Link, from company ifm;

- parallel multiple values transmission - sensors IO-Link may contain several transducers in the housing and transmit data parallel, what is allowed by communication standard (in fig. 12 is shown an example of process monitoring sensor and temperature measuring and counter total quantity in one integrated sensor, transmitting data with one three-wire cable; it allows accurate flow measurement, input and medium temperature, is characterized by high accuracy, repeatability and measurement dynamics, has switching, analog and pulse outputs; sensor SM9000 with configurable IO-Link s classified by the manufacturer as smart sensor);

- rapid sensor replacements - Master IO-Link module saves the complete configuration with the connected sensors parameters, thanks to which during a sensor replacement the previous parameters are automatically loaded to the new sensor;

- security - blocking through the network IO-Link parameters change by unauthorised users - setting up sensor, control buttons can be locked via standard parameterization, to prevent incorrect sensor settings by the operating personnel; parameters documentation can be verified at any time; 
- identification - sensors operate IO-Link are unequivocally identified by Vendor ID and Device ID -this ensures the use of only original spare parts.

a)

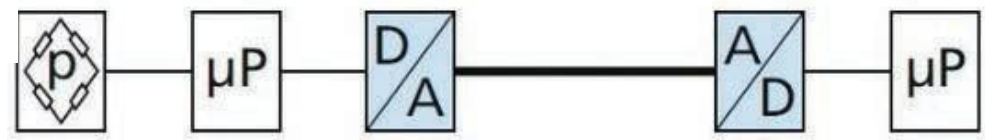

b)

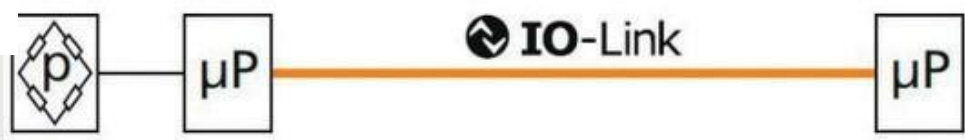

$\Delta$ Fig. 10. IO-Link sensor measuring path:

a) analog transmission,

b) digital transmission [32]

Fig. 11. Pressure sensor with display PN016A [33]
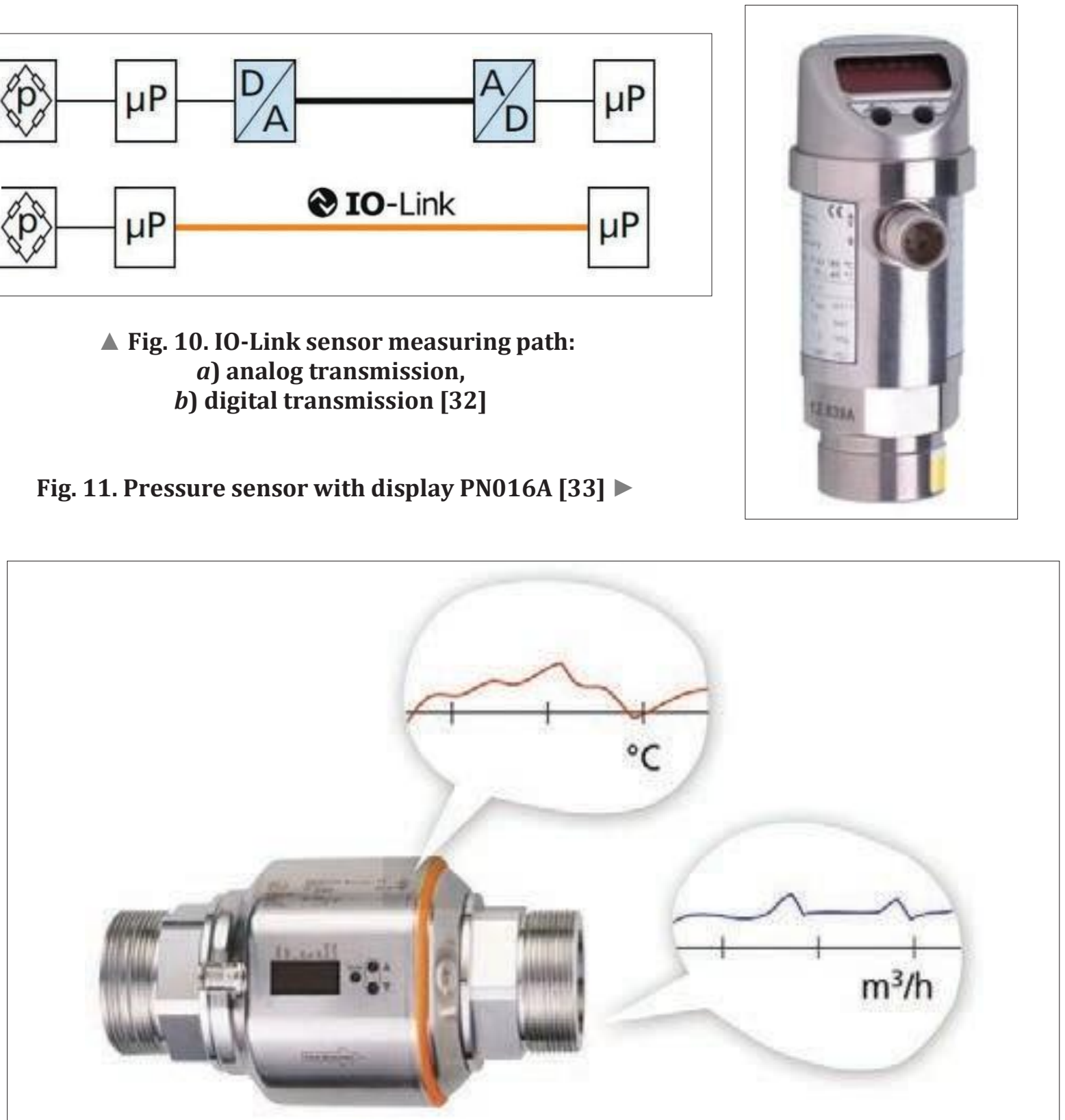

Fig. 12. Electromagnetic flow meter SM9000 [34]

IO-Link system allows the transfer not only the process data, but also diagnostic data (e.g. cable break or short circuit) which can be monitored during continuous operation.

\section{Summary}

Provided examples show that the progressive changes in sensors and measuring systems should be expected. These changes will be directed at the increase of independence and autonomy of measurement systems in accordance with the concept of edge machining. It will be necessary to increase the computing power of microcontrollers handling sensors and implementation of more and more advanced (transformable/ adaptive/self-improving) algorithms. Communication functionality will also be developed to facilitate cooperation (data exchange) with cloud environments. All these changes will require modification, or actually a new focus on modern measurement architectures creation and - as it seems - a complete change of the current concept/strategy of monitoring and supervision systems. 


\section{REFERENCES}

[1] Villalonga A. et al. "Condition-based Monitoring Architecture for CNC Machine Tools based on Global Knowledge". IFACPapersOnLine. 51, 11 (2018): 200-204, https://doi.org/10.1016/j.ifacol.2018.08.259.

[2] Tao W., Jiang Y. "Research on Intelligent Information Acquisition and Monitoring Method of NC Machine Tool Processing". Proceedings of the 2019. $3^{\text {rd }}$ International Forum on Environment, Materials and Energy (IFEME 2019), https://doi.org/ifeme19.2019.96.

[3] Luo B. et al. "Early Fault Detection of Machine Tools Based on Deep Learning and Dynamic Identification". IEEE Transactions on Industrial Electronics. 66, 1 (January 2019): 509-518, https://doi.org/10.1109/TIE.2018.2807414.

[4] Śniegulska-Grądzka D., Nejman M., Szulewski P. „Aktywne systemy monitorowania procesu skrawania dla Industry 4.0”. Mechanik. 3 (2018): 183-189, https://doi.org/10.17814/mechanik.2018.3.34.

[5] Zheng P. et al. "Smart manufacturing systems for Industry 4.0: Conceptual framework, scenarios, and future perspectives". Frontiers of Mechanical Engineering. 13, 2 (June 2018): 137-150, https://doi.org/10.1007/s11465-018-0499-5.

[6] Szulewski P. „Oprogramowanie i systemy czujników fundamentem koncepcji przemysłu 4.0”. Mechanik. 5-6 (2019): 346-352, https://doi.org/10.17814/mechanik.2019.5-6.40.

[7] Ambhorea N. et al. "Tool Condition Monitoring System: A Review". Materials Today Proceedings. 2, 4-5 (2015): 3419-3428, https://doi.org/10.1016/i.matpr.2015.07.317.

[8] Chung K.T., Geddam A. "A multi-sensor approach to the monitoring of end milling operations". Elsevier Journal of Materials Processing Technology. 139, 1-3 (20 August 2003): 15-20, https://doi.org/10.1016/S0924-0136(03)00175-4.

[9] Groover M.P. "Automation, Production Systems, and Computer-Integrated Manufacturing". 3rd edition. NJ, USA: Prentice Hall Press Upper Saddle River, 2007, ISBN: 0132393212.

[10] Soloman S. “Sensors Handbook”. NJ, USA: McGraw-Hill, Inc., 2009, ISBN:00716057039780071605700.

[11] Fortuna L. et al., „Soft Sensors for Monitoring and Control of Industrial Processes”. Springer Science \& Business Media. 271 (31 may 2007): 167-182.

[12] Villalonga A. et al. "Industrial cyber-physical system for condition-based monitoring in manufacturing processes". IEEE Industrial Cyber-Physical Systems (ICPS). 2018, https://doi.org/10.1109/ICPHYS.2018.8390780.

[13] Civerchia F. et al. "Industrial Internet of Things monitoring solution for advanced predictive maintenance applications". Journal of Industrial Information Integration. 7 (September 2017): 4-12, https://doi.org/10.1016/j.jii.2017.02.003.

[14] Sandeep P., Kumar M. "The Process Model for Shop Floor Management Implementation". International Journal of Engineering Science and Computing. (April 2017): 10775-10779, https://doi.org/10.7508/AIEM-V2-N1-40-46.

[15] Szulewski P. „Efektywne łączenie systemów podstawą inteligentnej produkcji”. Mechanik. 1 (2018): 7-11, https://doi.org/10.17814/mechanik.2018.1.1.

[16] Yamasaki H. "What are the intelligent sensors". Handbook of Sensors and Actuators. Elsevier. 3 (1996), https://doi.org/10.1016/S1386-2766(96)80026-0, 1-17.

[17] Brecher C. et al. "The need of dynamic and adaptive data models for cyber-physical production systems". Cyber-Physical Systems: Foundations, Principles and Applications (H. Song, D. Rawat, S. Jeschke, C. Brecher ed.). Academic Press, 2017, 321338.

[18] Morris A.S., Langari R. "Measurement and Instrumentation" (2nd ed.) "Theory and Application". Chapter 10, Academic Press, 2016, 289-314, https://doi.org/10.1016/B978-0-12-800884-3.00010-1.

[19] Wan J. et al. "Software-defined Industrial Internet of Things in the context of Industry 4.0". IEEE Sensors Journal. 16, 20 (October 15, 2016): 7373-7380, https://doi.org/10.1109/ISEN.2016.2565621.

[20] Barnaghi P. et al. "Semantics for the Internet of Things: Early progress and back to the future". International Journal on Semantic Web and Information Systems (IJSWIS). 8, 1 (2012): 1-21.

[21] Vural Özdemir V., Hekim N. "Birth of Industry 5.0: Making Sense of Big Data with Artificial Intelligence. The Internet of Things and Next-Generation Technology Policy”, https://doi.org/10.1089/omi.2017.0194 (access: 1 Jan 2018).

[22] Lu H. et al. "Brain Intelligence: Go beyond Artificial Intelligence". Mobile Networks and Applications. 23, 2 (April 2018): 368375.

[23] Pankesh P. et al., "On using the Intelligent Edge for IoT analytics”. IEEE Intelligent Systems. 32, 5 (September/October 2017): 64-69, https://doi.org/10.1109/MIS.2017.3711653.

[24] Daniel E.O. "Artificial Intelligence and Big Data". IEEE Intelligent Systems. 28 (February 2013): 96-99, https://doi.org/10.1109/MIS.2013.39.

[25] https://www.sandvik.coromant.com/pl-pl/products/silent tools turning/Pages/silent-tools-plus.aspx (access: 29.01.2019).

[26] https://www.sandvik.coromant.com/pl-pl/products/coromant capto/Pages/coromant-capto-plus.aspx (access: 24.01.2019).

[27] https://www.pcb.com/spec sheet.asp?m=8180-RE110A (access: 29.01.2019).

[28] https://www.kistler.com/en/applications/sensor-technology/cutting-forcemeasurement/rcd-rotating-dynamometers-tomeasure-cutting-forces (access: 29.01.2019).

[29] https://www.pro-micron.de/wp-content/uploads/2018/10/V25 spike Flyer EN final.pdf (access: 23.01.2019)

[30] https://easylaser.com/en-us/products/geometric-measurement/e940-machine-tool (access: 22.01.2019).

[31] https://www.schaeffler.pl/content.schaeffler.pl/pl/Produkty-iRozwiazania/Przemysl/portfolio produktow/mechatronika/lozyska fag variosense/index.jsp (access: 27.01.2019).

[32] https://www.ifm.com/pl/pl/shared/technologien/io-link/vorteile/przewaga-dzi\%C4\%99ki-io-link (access: 22.01.2019).

[33] https://www.ifm.com/pl/pl/product/PN016A (access: 22.01.2019).

[34] https://www.ifm.com/pl/pl/product/SM9000 (access: 22.01.2019). 